\title{
Using endogenous saccades to characterize fatigue in multiple sclerosis
}

\author{
Marisa Ferreira $^{\mathrm{a}, \mathrm{b}}$, Paulo A. Pereira ${ }^{\mathrm{b}, \mathrm{c}}$, Marta Parreira ${ }^{\mathrm{b}}$, Inês Sousa ${ }^{\mathrm{c}}$, José Figueiredo ${ }^{\mathrm{b}}$, João \\ J. Cerqueira ${ }^{\mathrm{d}, \mathrm{e}}$, Antonio F. Macedo ${ }^{\mathrm{a}, \mathrm{f}, \%}$ \\ a Vision Rehabilitation Lab.; Centre/Department of Physics and Optometry, University of Minho, Braga, Portugal \\ b Association "Todos com a Esclerose Multipla (TEM)", Braga, Portugal \\ c Centre of Mathematics, Department of Mathematics and Applications, University of Minho, Braga, Portugal \\ d Neurosciences Domain; Life and Health Sciences Research Institute, School of Health Sciences and ICVS/3B's Associate Laboratory, University of Minho, \\ Braga, Portugal \\ e Clinical Academic Centre (CCA), Hospital de Braga, Braga, Portugal \\ ${ }^{\mathrm{f}}$ Linnaeus University, Department of Medicine and Optometry, SE 39182 Kalmar, Sweden
}

\section{A R T I C L E I N F O}

\section{Keywords:}

Functional assessment

Saccades

Fatigue

Multiple Sclerosis

\begin{abstract}
A B S T R A C T
Purpose: Multiple Sclerosis (MS) is likely to cause dysfunction of neural circuits between brain regions increasing brain working load or a subjective overestimation of such working load leading to fatigue symptoms. The aim of this study was to investigate if saccades can reveal the effect of fatigue in patients with MS. Methods: Patients diagnosed with MS (EDSS < =3) and age matched controls were recruited. Eye movements were monitored using an infrared eyetracker. Each participant performed 40 trials in an endogenous generated saccade paradigm (valid and invalid trials). The fatigue severity scale (FSS) was used to assess the severity of fatigue. FSS scores were used to define two subgroups, the MS fatigue group (score above normal range) and the MS non-fatigue. Differences between groups were tested using linear mixed models.

Results: Thirty-one MS patients and equal number of controls participated in this study. FSS scores were above the normal range in 11 patients. Differences in saccade latency were found according to group $(\mathrm{p}<0.001)$ and trial validity $(\mathrm{p}=0.023)$. Differences were $16.9 \mathrm{~ms}$, between MS fatigue and MS non-fatigue, $15.5 \mathrm{~ms}$ between MS fatigue and control. The mean difference between valid and invalid trials was 7.5 ms. Differences in saccade peak velocity were found according to group $(\mathrm{p}<0.001)$, the difference between MS fatigue and control was $22.3^{\circ} \mathrm{s}$ and between MS fatigue and non-fatigue was $12.3^{\circ} \mathrm{s}$. Group was a statistically significant predictor for amplitude $(\mathrm{p}<0.001)$. FSS scores were correlated with peak velocity $(\mathrm{p}=0.028)$ and amplitude $(\mathrm{p}=0.019)$.

Conclusion: Consistent with the initial hypothesis, our study revealed altered saccade latency, peak velocity and amplitude in patients with fatigue symptoms. Eye movement testing can complement the standard inventories when investigating fatigue because they do not share similar limitations. Our findings contribute to the understanding of functional changes induced by MS and might be useful for clinical trials and treatment decisions.
\end{abstract}

\section{Introduction}

Multiple Sclerosis (MS) is a neurodegenerative disease characterized by demyelination and consequent reduction of neural conduction within the central nervous system leading to functional impairments (Archibald and Fisk, 2000; Kurtzke, 1983). MS represents the main cause of disability in non-traumatic neurological diseases in young adults (Sadovnick and Ebers, 1993) affecting up to 1 in 1000 people in some countries (Kingwell et al., 2013). In the Portuguese population a study from our group has found a prevalence of 40 cases per 100,000 inhabitants (Figueiredo et al., 2015). Consequences of MS go beyond the physical disability and symptoms of fatigue and depression are commonly reported at any stage of the disease (Janardhan and Bakshi, 2002). The MS Council, cited by Kos et al. (2008), define fatigue as "a subjective lack of physical and/or mental energy that is perceived by the individual or caregiver to interfere with usual and desired activities". Distressing symptoms of physical and mental fatigue have detrimental implications on career, employment and other activities, reducing significantly the quality of life of those affected (Frohman et al., 2005; Janardhan and Bakshi, 2002).

\footnotetext{
* Corresponding author at: Linnaeus University, Department of Medicine and Optometry, SE 39182 Kalmar, Sweden.

E-mail addresses: marisaborgesferreira@gmail.com (M. Ferreira), ppereira@math.uminho.pt (P.A. Pereira), martafgparreira@gmail.com (M. Parreira), isousa@math.uminho.pt (I. Sousa), minsk1enator@gmail.com (J. Figueiredo), jcerqueira@ecsaude.uminho.pt (J.J. Cerqueira), antonio.macedo@lnu.se (A.F. Macedo).
} 
Fatigue inventories are the most commonly used instruments to quantify, albeit subjectively, fatigue levels and their impact (Dittner, Wessely, \& Brown). Two commonly used inventories in MS are the Fatigue Severity Scale (FSS) and the Modified Fatigue Impact Scale (MFIS) (Dittner et al., 2004). However, according to a review by Chaudhuri and Behan in 2004, these inventories have some limitations. For example, they can introduce bias into a study population because of participants' knowledge that they are being studied (Hawthorne effect) (Chaudhuri and Behan, 2004). Given these limitations of inventories, alternative methods have been tried.

Some studies tried an objective characterization of fatigue using magnetic resonance imaging (Filippi et al., 2002; Genova et al., 2013; Mainero et al., 1999). In a study by Filippi et al., 2002 it was speculated that mental fatigue, in people with symptoms, might be explained by an increased activation of the cortical areas involved in attention. In a different study by the same group, authors hypothesized that some cortical reorganization might take place in patients with fatigue in order to maintain the functional capacity of the damaged brain (Rocca et al., 2002). This is also the most likely explanation for the lack of correlation between perceived fatigue and functional performance (Beatty et al., 2003). In people with reorganization, fatigue might become a "trait" contrary to what is expected in those without fatigue in which it can be considered a "state". Some authors distinguish "trait fatigue" from "state fatigue" (Genova et al., 2013; Parmenter et al., 2003; Roelcke et al., 1997). Genova et al. (2013) define "state" fatigue as a transient condition, which can change with time and can fluctuate based on both internal and external factors. State fatigue can be measure with, for example, a visual analogue scale. "Trait" fatigue refers to a more stable state in an individual and is not likely to change significantly over time. Trait fatigue is normally self-reported and can be quantified with the FSS scale (Genova et al., 2013). In this manuscript, when the word fatigue is used alone we refer to trait fatigue.

Recent reports gave evidence that saccadic eye movements can be used to study fatigue in MS (Finke et al., 2012; Matta et al., 2009). However, these findings need confirmation and other approaches to avoid limitations of previous studies. In the case of the study by Matta et al. (2009), all patients have been diagnosed with internuclear ophthalmoplegia (INO). Because of that, the authors speculate that mechanic disconjugacy of the eye movements observed in their participants is likely to be measuring not only fatigue but also oculomotor problems (Matta et al., 2009). In the study by Finke et al. (2012), patients were divided according with their FSS score in MS fatigue and MS non-fatigue (Finke et al., 2012). The MS fatigue group showed longer saccade latencies than the other two groups (nonfatigue and control) in a $10 \mathrm{~min}$ exogenous (reflexive) saccade task. Peak velocity and amplitude in fatigued patients were similar to controls and non-fatigued patients at the beginning of the task, but that changed over time. This study showed that patients with fatigue symptoms are more prone to fatigability but did not clarify if saccades would assess directly fatigue symptoms. Also, it is uncertain if this task would assess, physical mental, or both types of fatigue. It seems, therefore, that different paradigms might provide further insight in how fatigue affects saccades.

Endogenous saccades (goal-oriented) require additional top-down control (Liversedge et al., 2011; Walker et al., 1997, 1995, 2000). The neural systems controlling visual attention appear to overlap with those controlling eye movements and is not possible to make an eye movement without making a shift of attention (Kristjánsson, 2011; Summer, 2011). There is evidence from positron emission tomography that metabolic activity in the frontal lobes and the anterior cingulate is altered in patients with fatigue symptoms. These are areas also involved in attention, executive functions and eye movements planning (Liversedge et al., 2011; Summer, 2011). Therefore, endogenous saccade paradigms as the one used by Fielding et al. (2009) should be able to distinguish patients with fatigue from those without fatigue.

A saccade paradigm combining the presentation of an endogenous attentional cue (that can be "valid" or "invalid", see Refs (Posner Cuieng Task, 2016; Posner, 1980)) with the execution of an exogenous saccade (in response to the appearance of a visual target) is likely to show increased latencies in fatigued patients due to attention problems associated with fatigue (Posner Cuieng Task, 2016; Posner, 1980). Moreover, fatigue would cause reduction in peak velocity mostly due to altered neural activity in areas frontal cortical areas and the anterior cingulate cortex (Liversedge et al., 2011). Therefore, the aim of this study was to investigate endogenous generated saccades in MS patients with fatigue symptoms. We hypothesized that patients with fatigue would show changes in oculomotor performance, in particular increased latency and reduced peak velocity, reflecting trait fatigue.

\section{Methods}

\subsection{Participants}

MS participants were recruited from the local hospital by their neurologist (author JJC). The inclusion criteria for MS participants were: age between 18 and 45 years old, relapsing remitting course, early stages of disease severity as measured by the Expanded Disability Status Scale $\leq 3$ (Kurtzke, 1983), normal or corrected to normal binocular visual acuity and not medicated to fatigue symptoms. Exclusion criteria were: on-going relapse/relapse in the previous month, presence of clinically diagnosed cognitive impairment, history of traumatic brain injury and/or stroke, depression (self-reported or detected during the study using the Beck Depression Inventory (Beck et al., 1988)), and clinically visible oculomotor abnormalities (e.g., nystagmus or INO). Controls were subject to equivalent exclusion criteria. The institutional ethics committee at University of Minho reviewed the study. All participants were fully informed about the aim of the study and procedures involved, all provided free informed consent.

\subsection{Equipment}

Eye movements were monitored using a binocular eyetracker running at $250 \mathrm{~Hz}$ (RED250, SMIGmb, Teltow, Germany). The eyetracker has a spatial resolution $<0.4^{\circ}$, is controlled with iView $\mathrm{X}$ software (v2.8, August 2011, SMIGmb, Teltow, Germany) and stimuli were presented on a $22 \mathrm{in.} \mathrm{LCD} \mathrm{monitor} \mathrm{running} \mathrm{at} 60 \mathrm{~Hz}$ (Dell $\mathrm{P} 2210$ ). The system is formed of two computers connected by a high speed Ethernet. A computer controlled the eyetracker and a second computer controlled the stimulus presentation. A Matlab SDK provided by SMI and elements of the Psychophysics toolbox were used for running the experiment (Brainard, 1997; Pelli, 1997). Code for data analysis was also written in Matlab (The MathWorks, Inc., Natick, MA, USA).

\subsection{Procedure for measuring saccades}

Experiments were performed in a dimly lit room ( $~ 10$ lux) and stimulus Michelson contrast was $90 \%$. One or two blocks of 8 practice trials were performed before data collection to make participants familiar with calibration and with the task. A 5-point calibration procedure was applied, only participants with calibration accuracy (mean deviation for the expected position) of $1^{\circ}$ or less in $\mathrm{x}$-axis and $\mathrm{y}$ axis were considered. Participants were seated $70 \mathrm{~cm}$ from the monitor with their head restrained with a headband attached to the seat, as shown in Fig. 1. Saccades were performed $10^{\circ}$ to the left or to the right of the fixation target using the paradigm shown in Fig. 1. The paradigm consisted of 3 steps. In step 1 subjects had to fixate a centrally located target (cross) during $850 \mathrm{~ms}$, in step 2 the cross was replaced by a left or right pointing arrow illuminated by $500 \mathrm{~ms}$ and in step 3, subjects were presented with a peripheral target (cross) duration $1500 \mathrm{~ms}$, appearing at $10^{\circ}$ to the left or the right of the fixation target (in a 

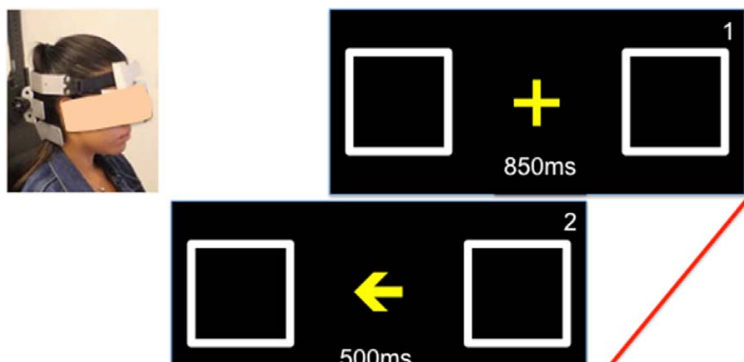

$500 \mathrm{~ms}$
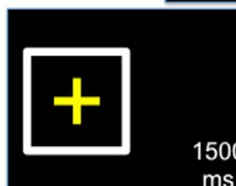

500

ms

Fig. 1. The figure shows the endogenous generated saccades paradigm and the headband restraining head movements (top-left). Continuous fixation during 10 monitor frames in a gaze-contingent fixation box in the middle of the screen $(200 \times 200$ pixel $)$ was required before each trial. Each trial started in step 1 during which a central fixation cross presented for $850 \mathrm{~ms}$ followed by step 2 in which an arrow (cue) was presented for $500 \mathrm{~ms}$ and in step 3 the target appeared $10^{\circ}$ to the right or left of the central cue. During step 2, the cue direction determinates the trial "validity". When the cue points to the direction of the target trials are "valid" and when the cue points to the direction contrary of the target trials are "invalid".

random way). Trials were defined as "valid" if the arrow in step 2 was pointing in the same direction as the target, shown in Fig. 1, and "invalid" if the arrow was pointing in the opposite direction of the target. Participants were instructed to: "fixate the central cross first, keep fixating the arrow until a peripheral target appears and then look at the target as quickly as possible", the target was a $30 \times 30 \mathrm{~mm}$ cross. Each subject performed 40 trials, $80 \%$ valid trials and $20 \%$ invalid trials, this division was suggested by Posner (1980). See video still for an example of the paradigm.

Supplementary material related to this article can be found online at http://dx.doi.org/10.1016/j.msard.2017.01.014.

\subsection{Neuropsychological inventories}

Fatigue severity was assessed with the Fatigue Severity Scale (FSS). The FSS scale consists of 9 questions about the severity of fatigue symptoms, categorized from strongly disagrees to strongly agrees by the subject (Krupp et al., 1989). Higher scores represent higher fatigue severity. The impact of fatigue in daily living was assessed through the Modified Fatigue Impact Scale (MFIS). In this inventory patients rate the extent to which fatigue has affected their life in the past 4 weeks on a questionnaire consisting of 10 "physical" items, 10 "cognitive" items, and 20 "social" items, with 0 indicating "no problem" and 4 indicating "extreme problem" (Kos et al., 2005) (Portuguese version validated versions by Gomes (2011) Available: http://hdl.handle.net/1822/ 17841)). Higher scores represent higher fatigue impact. Both inventories have normative data for the Portuguese population that are $33(\mathrm{SD}=8.7)$ for the FSS and $23(\mathrm{SD}=12)$ for the MFIS. Results from the MS group were compared with the normative values and these inventories were only applied to patients.

A general test of cognitive functioning, the MOCA-Montreal Cognitive Assessment, was also applied. This test provides information about executive functions, visuospatial ability, working memory and attention (Hajek et al., 1997). The global MOCA score corresponds to the sum of correct responses in each dimension and higher scores correspond to better cognitive functioning (Nasreddine et al., 2005). The expected value for the Portuguese population is $26.4(\mathrm{SD}=2.2)$ (Freitas et al., 2010).

Symbol Digit Modalities Test (SDMT) was used to evaluate neurocognitive functions that underlie many substitution tasks, in-
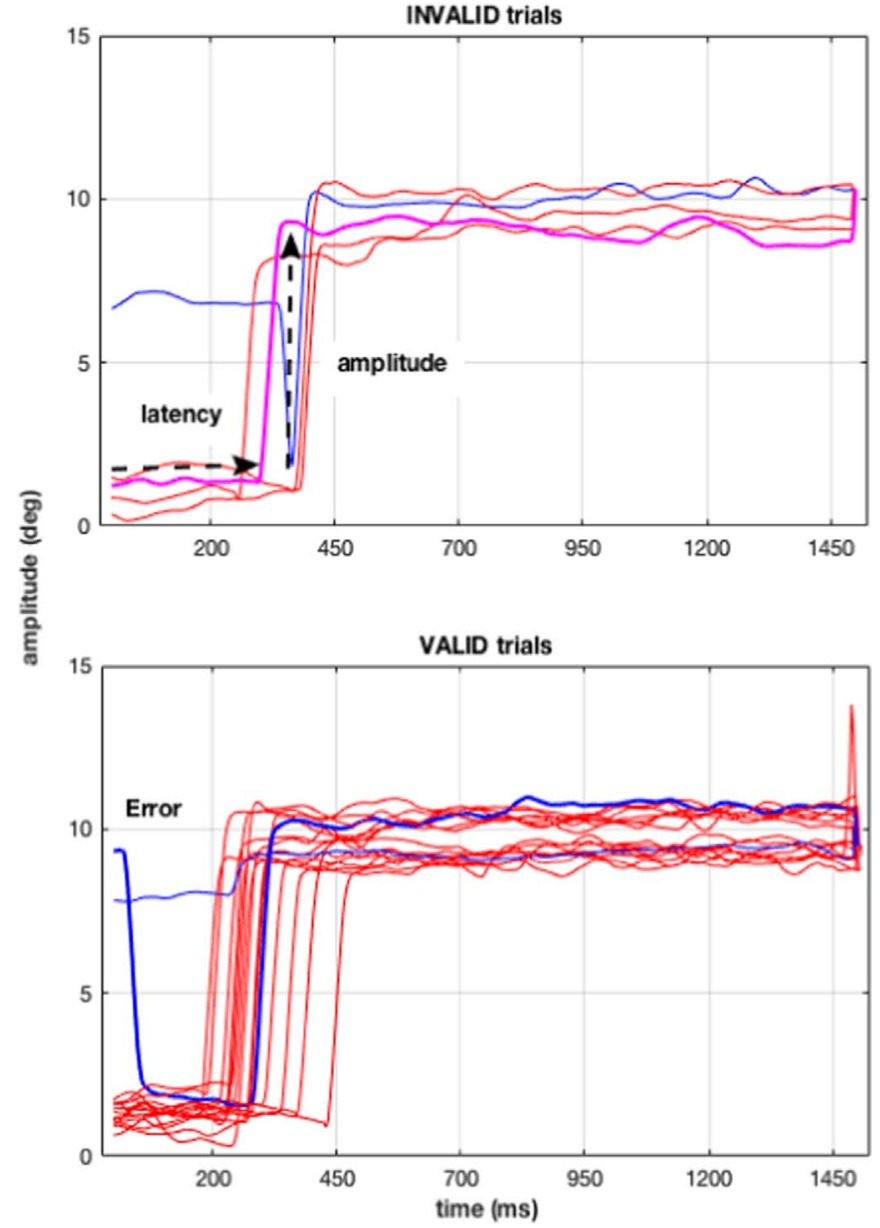

Fig. 2. The graph represents amplitude vs time output for "valid" and "invalid" trials. Lines show amplitude measured, during $1500 \mathrm{~ms}$ of target exposure (step 3 in Fig. 1), from the central fixation. The top graph is the output for invalid trials, the horizontal dashed arrow represents latency and the vertical represents amplitude for the trial with a pink line. The bottom graph is the output for valid trials showing an error with a blue line. This trial is considered an error because the amplitude of the eye movement was already approximately $10^{\circ}$ when the target appeared (anticipatory).

cluding attention, visual scanning, and motor speed (Sheridan et al., 2006). In this test subjects are presented with a key that includes 9 numbers, each one paired with a different symbol. Below the key is an array of these same symbols in a pseudorandom order paired with empty spaces. Subjects must then provide the correct numbers that accompany the symbols as indicated in the key. The number of correct paired symbols corresponds to the total score. Higher scores correspond to better performance (da Costa Pinto, 2004; Sheridan et al., 2006).

\subsection{Eye movements analysis}

Eye movements were collected binocularly with the point-of-regard (POR) information being: (POR-RE+POR-LE)/2. Saccadic variables analysed were latency, peak velocity and amplitude. Latency represents the time from stimulus appearance until the reaction of the eyes moving towards the target. Amplitude was measured as the absolute distance in degrees from the start position to the end position of the eye. Both amplitude and latency are represented in Fig. 2.

For analysed trials, saccade detection was performed after smoothing xy positions with a 5 sample moving average. This method has been proposed by others to reduce noise (Engbert and Kliegl, 2003). After smoothing, eye velocity and acceleration were computed, saccades were detected using the velocity threshold of $30^{\circ} / \mathrm{s}$ and/or acceleration 
threshold of $8500^{\circ} / \mathrm{s}^{2}$ with a minimum duration of $12 \mathrm{~ms}$ as used in the previous literature (Macedo et al., 2008, 2011). First saccades (detected after the target was visible, step 3 in Fig. 1) with amplitude less than $0.6^{\circ}$ were ignored (considered microsaccades (Martinez-Conde et al., 2004)) and the next saccade in the same trial was analysed. Trials were counted as errors if they meet any of the following criteria: i) the eye was at the target position before it was presented, ii) latency was above $799 \mathrm{~ms}$ (delayed saccades) or below $100 \mathrm{~ms}$ (anticipatory saccades).

\subsection{Statistical analysis}

A minimum of $50 \%$ analysed trials was required per subject (20 trials). The effect of group, validity and their interaction was tested with linear mixed model analysis (IBM SPSS Statistics for Windows, Version 22.0. Armonk, NY: IBM Corp). Linear mixed models are an alternative to ANOVA with demonstrated advantages when analysing, for example, reaction times in visual attention experiments (Kliegl et al., 2010). For the purpose of this study each saccade parameter was defined as "dependent variable" (e.g. latency). Participants were considered "random factors" and "group" (MS fatigue, MS non-fatigue and Control) were considered "fixed factors". "Validity" (e.g. valid-cue vs invalidcue) was defined as fixed factor. Bonferroni correction was applied when the number of comparisons was 3 or more. Means described and in graphs are the estimated marginal means (EMM=mean response for each factor, adjusted for any other variables in the model) and their standard errors (SE) for the specified factors. Correlations between outcome variables were tested; standard deviation (SD) is also used as measure of data dispersion.

\section{Results}

We present the data of 31 participants (19 females) with MS and 31 healthy controls (15 females), in both groups the mean age 36 years $(\mathrm{SD}=6)$. Demographic characteristics of the MS participants, mean values for FSS, MFIS, and MOCA are reported below. FSS scores were used to define two subgroups, the MS fatigue group (FSS score outside normal range) and the MS non-fatigue. Subjects were considered fatigued or having impact of fatigue if their score was out of the normal range for the Portuguese population (Gomes, 2011 Available: http://hdl.handle.net/1822/17841).

\subsection{Neuropsychological results}

In the FSS inventory 11 participants (36\%, 6 females) were outside the normal range and were considered fatigued (MS fatigue). The mean age of the fatigued group was 40 years $(\mathrm{SD}=4)$, mean time since diagnosis was 91 months ( $\mathrm{SD}=57)$. The mean age for the MS nonfatigue group was 34 years $(\mathrm{SD}=6)$ and time since diagnosis 83 months ( $\mathrm{SD}=63)$. In the MFIS, 15 MS participants scored outside the normal range. The mean MFIS score was $51(\mathrm{SD}=12)$ for the MS fatigue group and $20(\mathrm{SD}=16)$ for the MS non-fatigue.

In the MOCA test both MS groups showed statistically significant differences when compared with normal values. The MS non-fatigue group scored $24.9(\mathrm{SD}=2.6, \mathrm{t}(19)=-2.6, \mathrm{p}=0.017)$ and the MS fatigue scored $22.7(\mathrm{SD}=2.1, \mathrm{t}(10)=-5.9, \mathrm{p}<0.000)$. The difference of 2.2 points between MS groups was statistically significant (Mann-Whitney $U$ test, $\mathrm{p}=0.03$ ).

\subsection{Oculomotor results}

The total number of trials analysed was 2122 (13\% of the total were discarded). The median percentage of errors [\% of errors=(number of trials analysed/number of errors)* 100 ] was $2.7 \%$ in the control group, $5.4 \%$ in the non-fatigue group and $10 \%$ in the fatigue group. The percentage of trials and errors discarded varies largely between studies and our results are within the expected range (Gorea et al., 2014). The

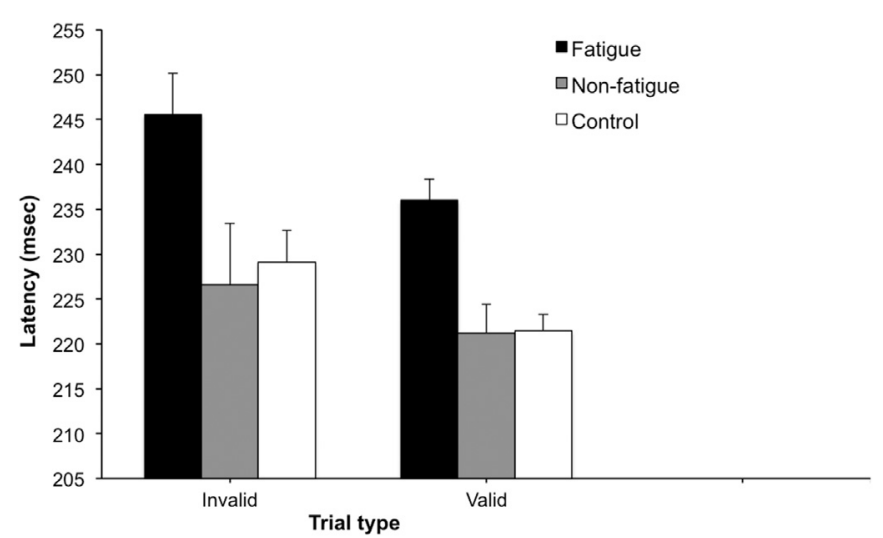

Fig. 3. Saccade latency for the three groups of participants by validity. MS fatigue (black columns), MS non-fatigue (grey columns) and control group (white columns). Columns represent the estimated marginal means (EMM) and error bars their standard error.

percentage of errors was higher in both MS groups when compared with controls (control $v$ s fatigue, chi-square test $(1)=5.4, \mathrm{p}=0.02$, and control vs non-fatigue, chi-square test $(1)=5.2, \mathrm{p}=0.022$ ).

The mean latency (EMM for valid and invalid trials values collapsed) was $240.8 \mathrm{~ms}(\mathrm{SE}=3.8)$ in $\mathrm{MS}$ fatigue group, $223.9 \mathrm{~ms}$ $(\mathrm{SE}=2.6)$ in $\mathrm{MS}$ non-fatigue group and $225.3 \mathrm{~ms}(\mathrm{SE}=2.0)$ in the control group. Results for the saccade latency by validity and group are shown in Fig. 3. Two main effects were found: i) a main effect of validity with $\mathrm{F}(1,1838)=5.2(\mathrm{p}=0.023)$, latencies were relatively prolonged following invalid cues with a mean difference for valid cues of $7.5 \mathrm{~ms}(\mathrm{SE}=3.3)$, and ii) a main effect of group, with $\mathrm{F}(2,1838)=7.8$ (p $<0.001$ ), latencies prolonged for MS fatigue participants. The mean difference between MS fatigue and control was $15.5 \mathrm{~ms}(\mathrm{SE}=4.2$, $\mathrm{p}=0.001$ ), between MS fatigue and MS non-fatigue was $16.9 \mathrm{~ms}$ ( $\mathrm{SE}=4.6, \mathrm{p}=0.001)$. There was not interaction between trial type (valid vs invalid) and group (control, MS fatigue and MS non-fatigue). Multiple linear regression was tested with age, BDI, SMDT (correct responses) and gender. None of these variables showed any significant effects on saccade latency (a separated analysis for valid, invalid and both was also conducted).

The mean peak velocity (EMM valid and invalid trials collapsed) was $301.4^{\circ} / \mathrm{s}(\mathrm{SE}=4.2)$ in $\mathrm{MS}$ fatigue group, $313.6^{\circ} / \mathrm{s}(\mathrm{SE}=2.9)$ in the MS non-fatigue group and $323.8^{\circ} / \mathrm{s}(\mathrm{SE}=2.2)$ in the control group. Results of peak velocity by direction are shown in Fig. 4. For peak velocity a main effect of group was found, $F(2,1838)=27.2(p<0.001)$. Peak velocity in controls was higher than in the MS non-fatigue, mean difference $11.8^{\circ} / \mathrm{s}(\mathrm{SE}=2.9, \mathrm{p}<0.001)$, and higher than in the MS fatigue, mean difference $26.2^{\circ} / \mathrm{s} \quad(\mathrm{SE}=3.7, \mathrm{p}<0.001)$. The mean

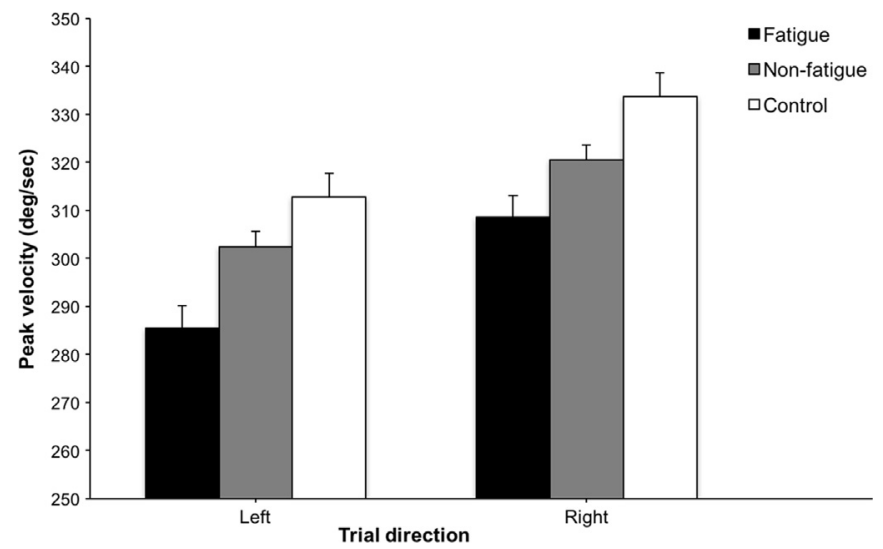

Fig. 4. Saccade peak velocity for the three groups of participants by direction. MS fatigue (black columns), MS non-fatigue (grey columns) and control group (white 10 columns). Columns represent the estimated marginal means (EMM) and error bars their standard error. 
difference between the MS fatigue group and the MS non-fatigue was $14.4^{\circ} / \mathrm{s}(\mathrm{SE}=4.0, \mathrm{p}=0.01)$. Peak velocity for right trials was significantly higher than for left trials $\mathrm{F}(1,1838)=50.5(\mathrm{p}<0.001)$, the estimated difference between the two directions was $20.7^{\circ} / \mathrm{s}(\mathrm{p}<0.001)$, there was no interaction "direction $\times$ group" indicating that the asymmetry (left-right) in peak velocity was equivalent for the 3 groups.

The mean saccade amplitude (EMM valid and invalid trials collapsed) was $8.9^{\circ}(\mathrm{SE}=0.06)$ in $\mathrm{MS}$ fatigue group, $9.1^{\circ}(\mathrm{SE}=0.04)$ in MS non-fatigue group and $8.7^{\circ}(\mathrm{SE}=0.03)$ in the control group. For amplitude a main effect of group was found, $\mathrm{F}(2,1838)=24.9$ ( $\mathrm{p}<$ 0.001 ), with amplitude significantly different amongst the 3 groups. The mean difference between control group and the MS fatigue group was $0.17^{\circ}(\mathrm{SE}=0.04, \mathrm{p}=0.029)$ and between control and the MS nonfatigue was $0.36^{\circ}(\mathrm{SE}=0.05, \mathrm{p}<0.001)$. The mean difference MS nonfatigue and MS fatigue was $0.19(\mathrm{SE}=0.07, \mathrm{p}=0.019)$. There was also an effect of direction, $\mathrm{F}(1,1838)=160(\mathrm{p}<0.001)$, with mean amplitude for left trials of $8.6^{\circ}(\mathrm{SE}=0.04)$ and for right trials of $9.2^{\circ}(\mathrm{SE}=0.04)$, the mean difference was $0.65^{\circ}(\mathrm{SE}=0.05)$. There was no interaction between direction and group. Given the effect of group on amplitude we computed the mean amplitude for right and for left trials for each participant. Then we selected the direction with the smaller mean amplitude and the direction with larger mean amplitude for each individual and computed the ratio between both. Differences in this ratio between the 3 groups were not statistically significant (KruskalWallis $\mathrm{H}$ test, $\mathrm{p}=0.26$ ). These calculations were performed as a control indicator that differences for directions were not caused by the existence of underlying INO in any of the groups.

The relationship between amplitude and peak velocity for 3 participants, one from each group, is shown in Fig. 5. The relationship between these two variables for the range of amplitudes considered should be approximately linear (Baloh et al., 1975). The linear fitting is good for the control subject (squares) but not for the MS non-fatigue subject (circles) or MS fatigue subject (asterisks).

\subsection{Correlations between fatigue and saccades results}

There was a positive correlation between the impact of fatigue (MFIS scores) and the fatigue severity (FSS scores), $r=0.71(\mathrm{p}<0.001)$ indicating a strong association between subjective complaints obtained with inventories. This association indicates that patients with higher FSS scores report more impact of fatigue in their everyday life, reinforcing the idea that FSS scores reflect a trait.

There was a negative correlation between MOCA scores, $r=-0.4$ $(\mathrm{p}=0.014)$ and MFIS, indicating a mild association between impact of

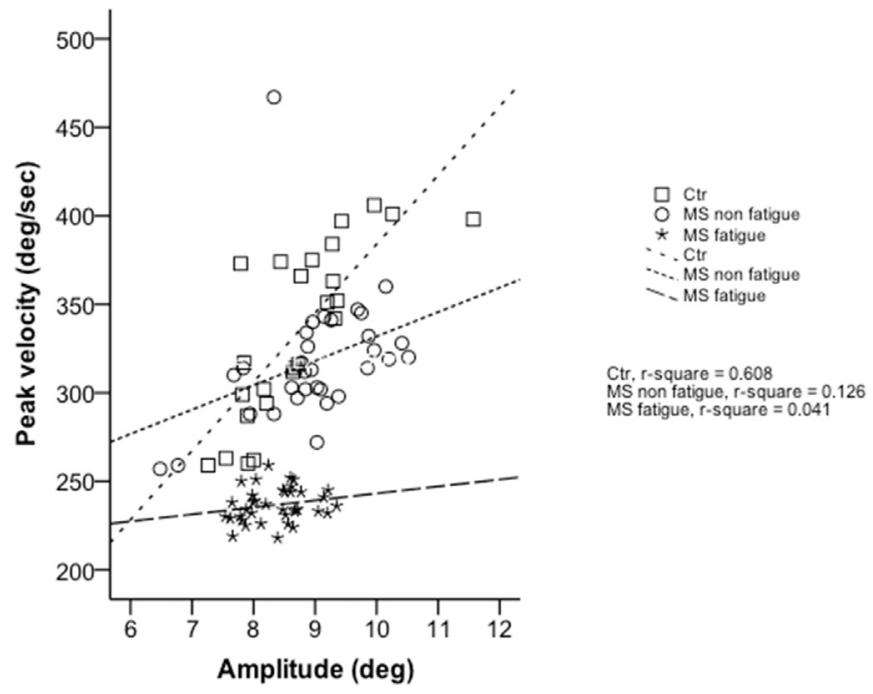

Fig. 5. The main sequence for 3 participants using valid and invalid trials. Control squares, MS non-fatigue - circles, MS-fatigue - asterisks. fatigue and general cognitive functioning. There was also a negative correlation between SDMT (number of correctly paired symbols) and latency, $r=-0.4(p=0.033)$. Fatigue severity (FSS score) was correlated negatively with peak velocity, $r=-0.4(p=0.028)$ and amplitude, $r=-0.4$ $(\mathrm{p}=0.019)$, these correlations are shown in Fig. 6 .

\section{Discussion}

In this study we investigated saccadic eye movements in patients diagnosed with MS using an endogenous generated saccade paradigm. Saccade latency, peak velocity and amplitude were compared between 3 groups: control, MS fatigue and MS non-fatigue to investigate if they are altered in MS patients with fatigue complaints. Results confirmed our prediction that fatigue symptoms would increase saccade latencies and reduce peak velocities. The functional paradigm used is likely to capture pre-motor changes in the oculomotor system (Finke et al., 2012) and requires top-down control of the eye movements (Fielding et al., 2009; Walker et al., 2000). Previous brain imaging studies showed that attention areas have altered activity in MS patients with fatigue symptoms (Filippi et al., 2002; Rocca et al., 2002; Roelcke et al., 1997). Therefore, we expected to find a larger gap between latencies, according with trial validity, for those with fatigue given the possible association between fatigue and attention deficits. However, we failed to find this effect.

Patients with fatigue symptoms exhibited increased saccade latencies when compared with patients without fatigue or healthy controls. Latency results were similar to those reported by Badham and Hutchinson when studying saccades in people with chronic fatigue syndrome (Badham and Hutchinson, 2013). Differences between MS patients and controls are also in line with other studies (Fielding et al., 2009; Finke et al., 2012; Walker et al., 1997). The paradigm used is likely to capture oculomotor problems and difficulties to move attention due to increased internal noise in the neuronal system caused by fatigue (Prsa et al., 2010; Straube et al., 1997). The negative correlation between latency and SDMT scores suggests association between latency and other cognitive performance measures. Evidence of increased latency caused by fatigue has also been found by Finke et al. in MS patients (Finke et al., 2012). In that study an exogenous saccade paradigm that induces fatigue was used and therefore their findings could be associated more with fatigability. In addition to the possible effects of fatigue in attention, we agree with explanation given by Finke et al. that other factors can contribute to increased latency. According with these authors eye movements are a measure of the efferent visual pathway and increased latencies can be explained, for example, by the impaired central muscle activation observed in patients with fatigue symptoms (Andreasen et al., 2009; Balcer et al., 2015). Other saccade measures, such as peak velocity, were consistent with the latency results.

Decreased saccadic peak velocity has been associated with mental and muscular fatigue (Schmidt et al., 1979). Our results shown a significant reduction in peak velocity in the MS fatigue group and that is in line with results obtained in other studies (Finke et al., 2012). Reduction in saccade peak velocity is likely to provide an accurate representation of neural activity because, contrary to other saccades parameters, its control is involuntary (Cazzoli et al., 2014). Animal studies confirmed that changes in movements' metrics are likely to be caused by internal sources of noise such as drowsiness, attention modulation and neuronal fatigue (Prsa et al., 2010; Straube et al., 1997). The right - left asymmetry that we found can be explained by eye dominance (Vergilino-Perez et al., 2012). Peak velocities tend to be higher to the ipsilateral side of the dominant eye. Approximately $66 \%$ of the population is right eye dominant (Eser et al., 2008) and therefore peak velocities were higher to right saccades.

Amplitude was different between MS groups and controls and was associated with severity of fatigue. Our amplitude results, for all groups, are in agreement with the expected saccade hypometria 

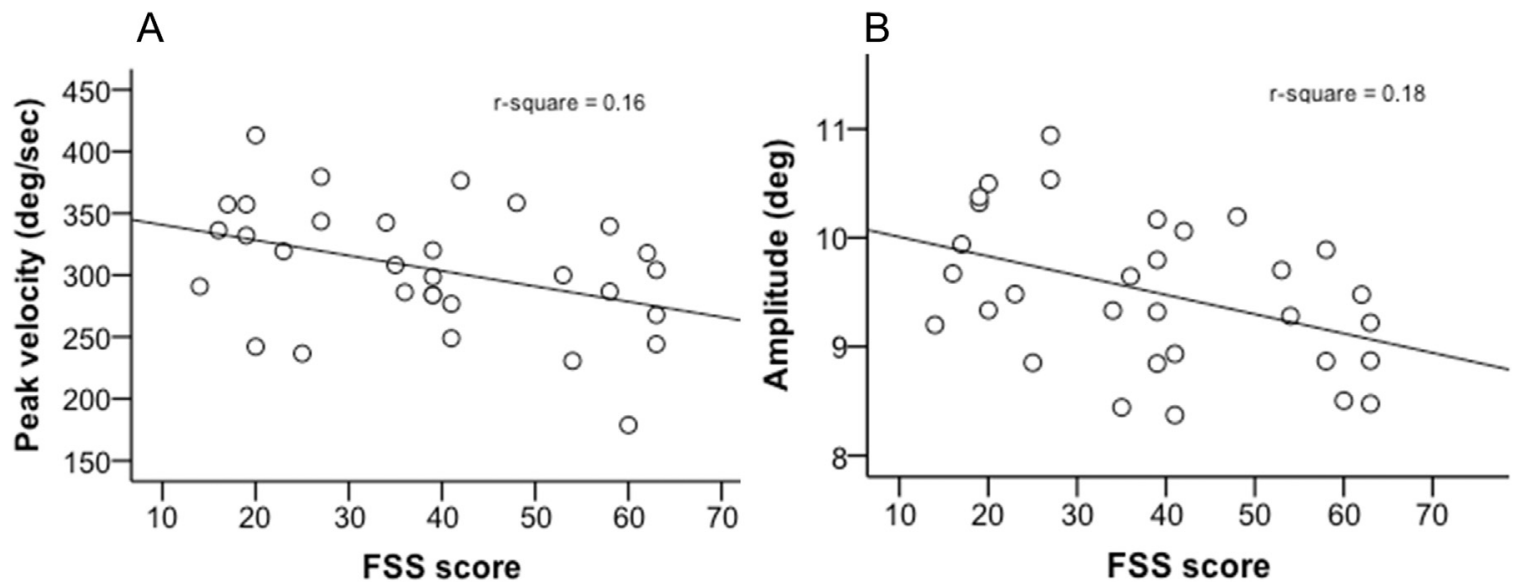

Fig. 6. Association between FSS absolute scores and saccade results. (A) peak velocity vs FSS score and (B) amplitude vs FSS score.

(undershooting the target) when a large saccade of $10^{\circ}$ or more is generated (Leigh and Kennard, 2004). Finke et al. found larger amplitudes amongst MS fatigue patients than in controls and MS non-fatigue during parts of the experiment (bin 2). These differences changed according with the period considered (Finke et al., 2012). Fielding et al. compared the gain of final eye position (defined as the ratio between the end point and the amplitude of the stimulus position) between MS patients and controls. Authors found consistent differences, although not statistically significant, between the two groups for valid and invalid trials (Fielding et al., 2009). Saccadic hypermetria or hypometria can be found in $25 \%$ or more of patients with MS but its relationship with fatigue requires further investigation (Barash et al., 1999; Serra et al., 2003; Tilikete et al., 2011).

We need to acknowledge that our study has some constraints that might limit the extent of our conclusions. The first is the lack of control for the effect of medication in saccades metrics; the second is that we were unable to perform reproducibility studies for saccade metrics. Both limitations can be filled in longitudinal studies.

In summary, testing saccadic eye movements can help with the characterization of neurological changes caused by MS as is the case of fatigue. Eye movement testing can complement the standard inventories because they do not share similar limitations. Future work to consolidate the main results about this subject should include evaluation of more advanced states of the disease and take in consideration the limitations pointed above. Paradigms used should aim to disentangle the effect of fatigue from disrupted attention. We believe that our findings contribute to the understanding of functional changes induced by MS and might be useful for clinical trials and treatment decisions.

\section{Conflicts of interest}

On behalf of all authors, the corresponding author states that there is no conflict of interest.

\section{Acknowledgments}

We would like to acknowledge that part of this work has been presented at 3rd International Porto Congress of Multiple Sclerosis, February 27-28, 2015, Porto, Portugal and ECEM 2015 | XVIII. European Conference on Eye Movements, August 16-21, 2015, Viena, Austria.

We thank the Multiple Sclerosis Association "Todos com a Esclerose Multiple (TEM)" and the Clinical and Academic Centre (CAA-Hospital de Braga) for their support financial support and for providing facilities for data collection, respectively.

We also acknowledge: i) Carla Sofia for recruiting all the MS participants and most of the controls, ii) Two anonymous reviewers for their opinion about an early version of this manuscript and iii) Liz Pearce for proofreading the manuscript.

Vision Rehabilitation Lab. receives founding from Shamir Portugal and from grant PTDC/DTP-EPI/0412/2012, Fundação para a Ciência e a Tecnologia, co-financiado pelo FEDER através do COMPETE.

\section{References}

Andreasen, A.K., Jakobsen, J., Petersen, T., Andersen, H., 2009. Fatigued patients with multiple sclerosis have impaired central muscle activation. Mult. Scler. 15 (7), 818-827. http://dx.doi.org/10.1177/1352458509105383.

Archibald, C.J., Fisk, J.D., 2000. Information processing efficiency in patients with multiple sclerosis. J. Clin. Exp. Neuropsychol. 22 (5), 686-701. http://dx.doi.org/ 10.1076/1380-3395(200010)22:5;1-9;ft686.

Badham, S.P., Hutchinson, C.V., 2013. Characterising eye movement dysfunction in myalgic encephalomyelitis/chronic fatigue syndrome. Graefes Arch. Clin. Exp. Ophthalmol. 251 (12), 2769-2776. http://dx.doi.org/10.1007/s00417-013-2431-3.

Balcer, L.J., Miller, D.H., Reingold, S.C., Cohen, J.A., 2015. Vision and vision-related outcome measures in multiple sclerosis. Brain 138 (Pt1), 11-27. http://dx.doi.org/ 10.1093/brain/awu335.

Baloh, R.W., Sills, A.W., Kumley, W.E., Honrubia, V., 1975. Quantitative measurement of saccade amplitude, duration, and velocity. Neurology 25 (11), 1065-1070.

Barash, S., Melikyan, A., Sivakov, A., Zhang, M., Glickstein, M., Thier, P., 1999. Saccadic dysmetria and adaptation after lesions of the cerebellar cortex. J. Neurosci. 19 (24), 10931-10939.

Beatty, W.W., Goretti, B., Siracusa, G., Zipoli, V., Portaccio, E., Amato, M.P., 2003. Changes in neuropsychological test performance over the workday in multiple sclerosis. Clin. Neuropsychol. 17 (4), 551-560. http://dx.doi.org/10.1076/ clin.17.4.551.27942.

Beck, A.T., Steer, R.A., Carbin, M.G., 1988. Psychometric properties of the Beck Depression Inventory: twenty-five years of evaluation. Clin. Psychol. Rev. 8 (1) 77-100.

Brainard, D.H., 1997. The psychophysics toolbox. Spat. Vis. 10 (4), 433-436.

Cazzoli, D., Antoniades, C.A., Kennard, C., Nyffeler, T., Bassetti, C.L., Muri, R.M., 2014. Eye movements discriminate fatigue due to chronotypical factors and time spent on task-a double dissociation. PLoS One 9 (1), e87146. http://dx.doi.org/10.1371/ journal.pone.0087146.

Chaudhuri, A., Behan, P.O., 2004. Fatigue in neurological disorders. Lancet 363 (9413), 978-988. http://dx.doi.org/10.1016/s0140-6736(04)15794-2.

da Costa Pinto, A, 2004. Diferenças de sexo em provas de memória operatória, memória episódica e teste de símbolos. Psicol. Educ. e Cult. 8 (1), 7-19.

Dittner, A.J., Wessely, S.C., Brown, R.G., 2004. The assessment of fatigue: a practical guide for clinicians and researchers. J. Psychosom. Res. 56 (2), 157-170. http:// dx.doi.org/10.1016/s0022-3999(03)00371-4.

Engbert, R., Kliegl, R., 2003. Microsaccades uncover the orientation of covert attention. Vis. Res. 43 (9), 1035-1045.

Eser, I., Durrie, D.S., Schwendeman, F., Stahl, J.E., 2008. Association between ocular dominance and refraction. J. Refract. Surg. 24 (7), 685-689.

Fielding, J., Kilpatrick, T., Millist, L., White, O., 2009. Control of visually guided saccades in multiple sclerosis: disruption to higher-order processes. Neuropsychologia 47 (7), 1647-1653. http://dx.doi.org/10.1016/j.neuropsychologia.2009.01.040.

Figueiredo, J., Silva, A., Cerqueira, J.J., Fonseca, J., 2015. MS prevalence and patients' characteristics in the district of Braga, Portugal. Neurol. Res. Int. 2015. http:// dx.doi.org/10.1155/2015/895163.

Filippi, M., Rocca, M.A., Colombo, B., Falini, A., Codella, M., Scotti, G., Comi, G., 2002. Functional magnetic resonance imaging correlates of fatigue in multiple sclerosis. NeuroImage 15 (3), 559-567. http://dx.doi.org/10.1006/nimg.2001.1011.

Finke, C., Pech, L.M., Sommer, C., Schlichting, J., Stricker, S., Endres, M., Paul, F., 2012. 
Dynamics of saccade parameters in multiple sclerosis patients with fatigue. J. Neurol. 259 (12), 2656-2663. http://dx.doi.org/10.1007/s00415-012-6565-8.

Freitas, S., Simões, M.R., Martins, C., Vilar, M., Santana, I., 2010. Estudos de adaptação do Montreal Cognitive Assessment (MoCA) para a população portuguesa. Aval. Psicoló. 9, 345-357.

Frohman, E.M., Frohman, T.C., Zee, D.S., McColl, R., Galetta, S., 2005. The neuroophthalmology of multiple sclerosis. Lancet Neurol. 4 (2), 111-121. http:// dx.doi.org/10.1016/s1474-4422(05)00992-0.

Genova, H.M., Rajagopalan, V., Deluca, J., Das, A., Binder, A., Arjunan, A., Wylie, G., 2013. Examination of cognitive fatigue in multiple sclerosis using functional magnetic resonance imaging and diffusion tensor imaging. PLoS One 8 (11), e78811. http://dx.doi.org/10.1371/journal.pone.0078811.

Gomes, L.R., 2011. Available: 〈http://hdl.handle.net/1822/17841〉. Validação da versão portuguesa da escala de impacto da fadiga modificada e da escala de severidade da fadiga na esclerose múltipla. (Master thesis). University of Minho. Retrieved from 〈http://hdl.handle.net/1822/17841〉 (Universidade do Minho).

Gorea, A., Rider, D., Yang, Q., 2014. A unified comparison of stimulus-driven, endogenous mandatory and 'free choice' saccades. PLoS One 9 (2), e88990. http:// dx.doi.org/10.1371/journal.pone.0088990.

Hajek, V.E., Gagnon, S., Ruderman, J.E., 1997. Cognitive and functional assessments of stroke patients: an analysis of their relation. Arch. Phys. Med. Rehabil. 78 (12), 1331-1337.

Janardhan, V., Bakshi, R., 2002. Quality of life in patients with multiple sclerosis: the impact of fatigue and depression. J. Neurol. Sci. 205 (1), 51-58.

Kingwell, E., Marriott, J.J., Jette, N., Pringsheim, T., Makhani, N., Morrow, S.A., Marrie, R.A., 2013. Incidence and prevalence of multiple sclerosis in Europe: a systematic review. BMC Neurol. 13, 128. http://dx.doi.org/10.1186/1471-2377-13-128.

Kliegl, R., Wei, P., Dambacher, M., Yan, M., Zhou, X., 2010. Experimental effects and individual differences in linear mixed models: estimating the relationship between spatial, object, and attraction effects in visual attention. Front. Psychol. 1, 238. http://dx.doi.org/10.3389/fpsyg.2010.00238.

Kos, D., Kerckhofs, E., Nagels, G., D'Hooghe, M., B., Ilsbroukx, S., 2008. Origin of fatigue in multiple sclerosis: review of the literature. Neurorehabil. Neural Repair 22 (1), 91-100. http://dx.doi.org/10.1177/1545968306298934.

Kos, D., Kerckhofs, E., Carrea, I., Verza, R., Ramos, M., Jansa, J., 2005. Evaluation of the Modified Fatigue Impact Scale in four different European countries. Mult. Scler. 11 (1), 76-80.

Kristjánsson, Á., 2011. The intriguing interactive relationship between visual attention and saccadic eye movements. In: Liversedge, S.P., Gilchrist, I.D., Everling, S. (Eds.), The Oxford Handbook of Eye Movements Vol. I. Oxford University Press, Oxford, UK.

Krupp, L.B., LaRocca, N.G., Muir-Nash, J., Steinberg, A.D., 1989. The fatigue severity scale. Application to patients with multiple sclerosis and systemic lupus erythematosus. Arch. Neurol. 46 (10), 1121-1123.

Kurtzke, J.F., 1983. Rating neurologic impairment in multiple sclerosis: an expanded disability status scale (EDSS). Neurology 33 (11), 1444-1452.

Leigh, R.J., Kennard, C., 2004. Using saccades as a research tool in the clinical neurosciences. Brain 127 (Pt3), 460-477. http://dx.doi.org/10.1093/brain/awh035.

Liversedge, S.P., Gilchrist, I.D., Everling, S., 2011. The Oxford Handbook of Eye Movements Vol. I. Oxford University Press, Oxford, UK.

Macedo, A.F., Crossland, M.D., Rubin, G.S., 2008. The effect of retinal image slip on peripheral visual acuity. J. Vis. 8 (14). http://dx.doi.org/10.1167/8.14.16.

Macedo, A.F., Crossland, M.D., Rubin, G.S., 2011. Investigating unstable fixation in patients with macular disease. Investig. Ophthalmol. Vis. Sci. 52 (3), 1275-1280. http://dx.doi.org/10.1167/iovs.09-4334.

Mainero, C., Faroni, J., Gasperini, C., Filippi, M., Giugni, E., Ciccarelli, O., Pozzilli, C., 1999. Fatigue and magnetic resonance imaging activity in multiple sclerosis. J. Neurol. 246 (6), 454-458.

Martinez-Conde, S., Macknik, S.L., Hubel, D.H., 2004. The role of fixational eye movements in visual perception. Nat. Rev. Neurosci. 5 (3), 229-240. http:// dx.doi.org/10.1038/nrn1348.
Matta, M., Leigh, R.J., Pugliatti, M., Aiello, I., Serra, A., 2009. Using fast eye movements to study fatigue in multiple sclerosis. Neurology 73 (10), 798-804. http:// dx.doi.org/10.1212/WNL.0b013e3181b6bbf4.

Nasreddine, Z.S., Phillips, N.A., Bedirian, V., Charbonneau, S., Whitehead, V., Collin, I., Chertkow, H., 2005. The Montreal Cognitive Assessment, MoCA: a brief screening tool for mild cognitive impairment. J. Am. Geriatr. Soc. 53, 695-699. http:// dx.doi.org/10.1111/j.1532-5415.2005.53221.x.

Parmenter, B.A., Denney, D.R., Lynch, S.G., 2003. The cognitive performance of patients with multiple sclerosis during periods of high and low fatigue. Mult. Scler. 9 (2), 111-118.

Pelli, D.G., 1997. The VideoToolbox software for visual psychophysics: transforming numbers into movies. Spat. Vis. 10 (4), 437-442.

Posner, M.I., 1980. Orienting of attention. Q. J. Exp. Psychol. 32 (1), 3-25.

Posner cuieng task, 2016. 30 September 2016). Retrieved from 〈https://en.wikipedia. org/w/index.php?Title=Posner_cueing_task \& oldid $=711789020\rangle$.

Prsa, M., Dicke, P.W., Thier, P., 2010. The absence of eye muscle fatigue indicates that the nervous system compensates for non-motor disturbances of oculomotor function. J. Neurosci. 30 (47), 15834-15842. http://dx.doi.org/10.1523/ jneurosci.3901-10.2010.

Rocca, M.A., Matthews, P.M., Caputo, D., Ghezzi, A., Falini, A., Scotti, G., Filippi, M., 2002. Evidence for widespread movement-associated functional MRI changes in patients with PPMS. Neurology 58 (6), 866-872.

Roelcke, U., Kappos, L., Lechner-Scott, J., Brunnschweiler, H., Huber, S., Ammann, W., Leenders, K.L., 1997. Reduced glucose metabolism in the frontal cortex and basal ganglia of multiple sclerosis patients with fatigue: a 18F-fluorodeoxyglucose positron emission tomography study. Neurology 48 (6), 1566-1571.

Sadovnick, A.D., Ebers, G.C., 1993. Epidemiology of multiple sclerosis: a critical overview. Can. J. Neurol. Sci. 20 (1), 17-29.

Schmidt, D., Abel, L.A., Dell'Osso, L.F., Daroff, R.B., 1979. Saccadic velocity characteristics: intrinsic variability and fatigue. Aviat. Space Environ. Med. 50 (4), 393-395.

Serra, A., Derwenskus, J., Downey, D.L., Leigh, R.J., 2003. Role of eye movement examination and subjective visual vertical in clinical evaluation of multiple sclerosis. J. Neurol. 250 (5), 569-575. http://dx.doi.org/10.1007/s00415-003-1038-8.

Sheridan, L.K., Fitzgerald, H.E., Adams, K.M., Nigg, J.T., Martel, M.M., Puttler, L.I., Zucker, R.A., 2006. Normative symbol digit modalities test performance in a community-based sample. Arch. Clin. Neuropsychol. 21 (1), 23-28. http:// dx.doi.org/10.1016/j.acn.2005.07.003.

Straube, A., Robinson, F.R., Fuchs, A.F., 1997. Decrease in saccadic performance after many visually guided saccadic eye movements in monkeys. Investig. Ophthalmol. Vis. Sci. 38 (13), 2810-2816.

Summer, P., 2011. Determinants of saccade latency. In: Liversedge, S.P., Gilchrist, I.D. Everling, S. (Eds.), The Oxford Handbook of Eye Movements I. Oxford University Press, Oxford, UK.

Tilikete, C., Jasse, L., Vukusic, S., Durand-Dubief, F., Vardanian, C., Pelisson, D. Vighetto, A., 2011. Persistent ocular motor manifestations and related visual consequences in multiple sclerosis. Ann. N.Y. Acad. Sci. 1233, 327-334. http:// dx.doi.org/10.1111/j.1749-6632.2011.06116.x.

Vergilino-Perez, D., Fayel, A., Lemoine, C., Senot, P., Vergne, J., Dore-Mazars, K., 2012. Are there any left-right asymmetries in saccade parameters? Examination of latency, gain, and peak velocity. Investig. Ophthalmol. Vis. Sci. 53 (7), 3340-3348. http:// dx.doi.org/10.1167/iovs.11-9273.

Walker, R., Kentridge, R.W., Findlay, J.M., 1995. Independent contributions of the orienting of attention, fixation offset and bilateral stimulation on human saccadic latencies. Exp. Brain Res. 103 (2), 294-310.

Walker, R., Deubel, H., Schneider, W.X., Findlay, J.M 1997. Effect of remote distractor on saccade programming: evidence for an extended fixation zone. J. Neurophysiol. 78 (2), 1108-1119.

Walker, R., Walker, D.G., Husain, M., Kennard, C., 2000. Control of voluntary and reflexive saccades, Exp. Brain Res. 130 (4), 540-544. 